\title{
EFFECTS OF THERMAL ENERGY, MECHANICAL ENERGY, AND SOLVENT ON CIPROFLOXACIN HYDROCHLORIDE MONOHYDRATE PHYSICOCHEMICAL PROPERTIES
}

\author{
Indah Widyastuti $^{1{ }^{* *},}$ Ahmad Ainurofiq ${ }^{2}$ and Sundani Nurono Soewandhi ${ }^{1}$ \\ ${ }^{1}$ School of Pharmacy, Institut Teknologi Bandung, Ganesha 10, Bandung, 40132, Indonesia \\ ${ }^{2}$ Department of Pharmacy, Universitas Sebelas Maret, Ir. Sutami 36A, \\ Surakarta, 57126, Indonesia \\ *E-mail: indah.widyastuti25@gmail.com
}

\begin{abstract}
Ciprofloxacin $\mathrm{HCl}$ is available in the form of anhydrate and monohydrate. Water content can affect the hydrolysis, hygroscopicity, bond, and crystal properties of an active substance. This study was aimed to observe the physicochemical phenomena that occur in ciprofloxacin $\mathrm{HCl}$ monohydrate because of thermal energy, mechanical energy, and solvent. Ciprofloxacin $\mathrm{HCl}$ monohydrate from two different producers were given treatments by thermal energy, mechanical energy, and solvent. Afterward, the ingredients were characterized using XRD, DSC, and SEM. Other than that, crystal habit, modulus of elasticity, and dissolution were assessed. The results of characterization before and after treatment were compared to observe any changes. Ciprofloxacin $\mathrm{HCl}$ monohydrate from two different producers showed similarities in physicochemical properties. Manufacture treatment, which includes thermal energy, mechanical energy, and solvent, affected the physicochemical characteristics of ciprofloxacin $\mathrm{HCl}$ monohydrate. The effect of thermal energy and solvent can change ciprofloxacin from hydrate to anhydrate, thus changed its dissolution level. Meanwhile, mechanical effect by grinding and compression can decrease crystallinity and change the particle size of ciprofloxacin $\mathrm{HCl}$ monohydrate, thus change its dissolution level. The results of this study showed that the process of manufacturing can change the physicochemical characteristics of ciprofloxacin $\mathrm{HCl}$ monohydrate.
\end{abstract}

Keywords: Ciprofloxacin $\mathrm{HCl}$ Monohydrate, Thermal Energy, Mechanical Energy, Solvent, Physicochemical property

ORASĀYAN. All rights reserved

\section{INTRODUCTION}

In the process of manufacturing pharmaceutical preparations, the quality of active pharmaceutical ingredient (API) highly affects the stability, effectivity, and safety of the drug. The unique molecular condition of each solid provides different physicochemical properties. ${ }^{1,2}$ API has been widely reported to be in the form of hydrate, which is a crystal solid containing a water molecule inside the crystal lattice. Based on its structure, hydrate crystal can be classified into isolated site hydrates, channel hydrates, and ion coordinated hydrates. Other than that, according to the amount of water molecule in a crystal lattice, hydrate can be classified into several classes, i.e. hemi-, mono, tri-, theta-, penta-, and hexahydrate. Ciprofloxacin hydrochloride is available in the form of anhydrate and monohydrate. ${ }^{3}$ Ciprofloxacin $\mathrm{HCl}$ monohydrate (Fig.-1) is the salt form of ciprofloxacin. This substance has the chemical name of monohydrochloride monohydrate salt from 1-cyclopropl-6-fluoro-1,4-dihydro-4-oxo-7-(1-piperazinyl-3quinoline carboxylic acid, monohydrochloride, monohydrate. Ciprofloxacin $\mathrm{HCl}$ monohydrate is a second-generation fluoroquinolone class antibiotic used in the medication of gram-negative bacterial infection and is included in BCS (Biopharmaceutics Classification System) class IV.

In every stage of the preparation manufacturing process, water can interact with API. The amount of water in API can be affected by RH and a certain temperature, thus increasing the affinity between active substance and a water molecule. The water content will affect hygroscopicity, bond, and crystal

Rasayan J. Chem., 12(4), 1973-1984(2019)

http://dx.doi.org/10.31788/RJC.2019.1245426

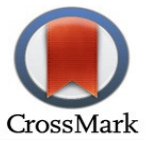


RASĀYAN J. Chem.

Vol. 12 | No. 4 |1973 - 1984| October - December | 2019

properties. ${ }^{4}$ This study characterized ciprofloxacin $\mathrm{HCl}$ monohydrate API from two different sources. This study was aimed to observe physicochemical phenomena that occur in ciprofloxacin $\mathrm{HCl}$ monohydrate caused by thermal energy, mechanical energy, and solvent from each ingredient. This study has not yet been studied, therefore new information regarding the physicochemical characteristics and possibilities in each ciprofloxacin hydrochloride monohydrate API can be put into consideration in determining parameters that need to be controlled during tablet manufacturing process.

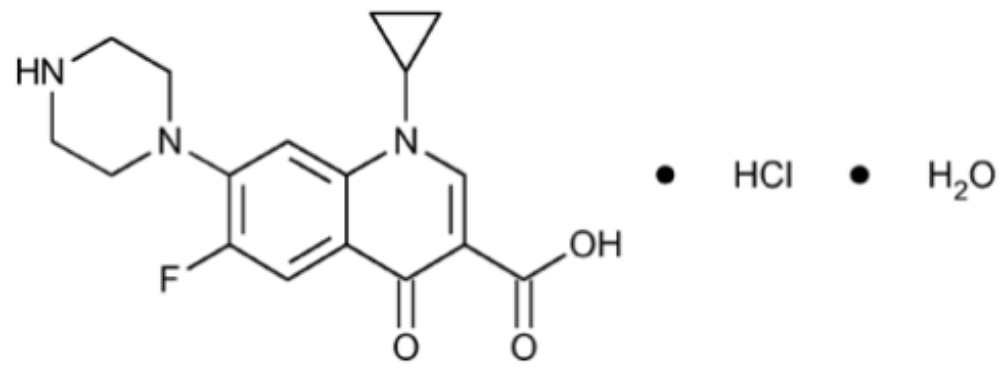

Fig.-1: Structure of Ciprofloxacin Hydrochloride Monohydrate ${ }^{45}$

As a consideration, several processes during pharmaceutical active ingredient manufacturing such as heat ${ }^{6,7}$, grinding and compressing process are manufacturing steps that involve mechanical energy ${ }^{8,9}$ and solvent $^{6}$ as the cause of solid transformation. Other than polymorph transformation, a solid transformation that can be caused by solvent include amorphous transition to crystalline, hydrate substance formation or solvate and substance derivatization, e.g. transformation of theophylline anhydrate to theophylline monohydrate in phosphate buffer solvent with $\mathrm{pH} 6$ or co-crystal formation of carbamazepine-saccharin using solvent evaporation technique. ${ }^{10}$

The solid transformation causes a difference in the physicochemical characteristics of the resulting solid. This was since every solid has its physicochemical characteristics. Several characteristics that can change include solubility ${ }^{11}$, dissolution rate and bioavailability ${ }^{12-14}$, hygroscopicity ${ }^{10}$, chemical stability and reactivity ${ }^{15}$, mechanical property. ${ }^{10,16}$ Unwanted solid transformation can be prevented during the manufacturing process and vice versa. If the solid transformation is wanted, then something should be done during the manufacturing process to initiate the process of transformation as expected. ${ }^{17}$

\section{Materials}

\section{EXPERIMENTAL}

Ciprofloxacin hydrochloride monohydrate was purchased from Aarti Drugs Limited (Mumbai, India) and Chemo S.A (Lugano, Switzerland), water, ethanol from Merck (Darmstadt, Germany), and hydrochloride acid was purchased from J.T Baker (NJ, USA).

\section{Methods}

\section{Effect of Thermal Energy}

A certain amount of sample was heated in a heat chamber (Binder, Germany) for one hour at 40, 110, and $180^{\circ} \mathrm{C}$. Heating results were characterized according to DSC and PXRD.

\section{Effect of Mechanical Energy}

\section{Effect of Grinding On Ciprofloxacin Hydrochloride Monohydrate}

A certain amount of sample was ground using Retsch RM 200 mortar grinder (Retsch, Germany) at 100 rpm speed for 180 minutes. The results of grinding were characterized according to DSC, PXRD, SEM and dissolution.

\section{Effect of Compression on Ciprofloxacin Hydrochloride Monohydrate}

A certain amount of sample was sifted using $140 \mu \mathrm{m}$ mesh. The sample was scaled at $500 \mathrm{mg}$ and was inserted into a die with $13 \mathrm{~mm}$ diameter, then compressed using a hydraulic press (Perkin Elmer, MA, 
USA) for 7 seconds. The compression force used was 4.9, 19.6, and $24.5 \mathrm{kN}$. The tablet was then characterized, including SEM, DSC, PXRD and dissolution.

\section{Effect of Solvent}

A certain amount of sample was dissolved in a solvent and evaporated at room temperature until the crystal formed. The solvent used was water and $96 \%$ ethanol. The crystal was characterized by crystal habit, DSC, PXRD and dissolution.

\section{Characterization of Solids}

X-ray Diffraction (PXRD)

PXRD data were collected using Bruker D8 Advance X-ray diffractometer (Madison, WI). A certain amount of sample was placed in a sample holder and was spread evenly. The analysis was performed

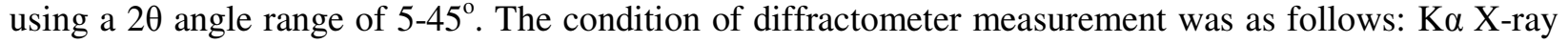
source; $\mathrm{Cu}$ target; $30.0 \mathrm{~mA}$ current; $25^{\circ} \mathrm{C}$ temperature; $10.4018 \mathrm{deg} /$ minute scan speed; $40.0 \mathrm{kV}$ voltage.

\section{Differential Scanning Calorimetry (DSC)}

The DSC studies were performed on a LINSEIS PT-1600 (Robbinsville, NJ), calibrated for cell constant and temperature using indium. Approximately 6-8 $\mathrm{mg}$ of sample was scaled and placed into aluminum pan. DSC instrument was arranged at $28-555^{\circ} \mathrm{C}$ with $10^{\circ} \mathrm{C} /$ minute of heating speed.

\section{Polarization Microscope}

The habit of the sample was investigated by polarization microscope BX-50 (Olympus, Tokyo, Japan). The sample was dispersed in paraffin liquid on object glass and was covered with a cover glass. The sample was observed using a polarization microscope with 400x magnification. The image was captured using AnalySIS GetIT software which was connected to the ocular lens of the microscope.

\section{Scanning Electron Microscope (SEM)}

The sample was placed on a sample holder and was layered with gold. The sample was observed in various magnification using a HITACHI SU3500 scanning electron microscope (Tokyo, Japan).

\section{Modulus of Elasticity Study}

A certain amount of sample was sifted using a $140 \mu \mathrm{m}$ mesh. The sample was scaled at $500 \mathrm{mg}$ and was inserted into a die with $13 \mathrm{~mm}$ diameter, then was compressed using a hydraulic press (Perkin Elmer, MA, USA) for 7 seconds. Compression force used were $4.9 ; 9.8 ; 14.7 ; 19.6 ; 24.5$; and $29.4 \mathrm{kN}$. The hardness and dimension of the tablet were measured. Afterward, tensile strength was measured, and the modulus of elasticity curve was made.

\section{Dissolution Study}

The sample was sifted using $140 \mu \mathrm{m}$ mesh and a certain amount of it was inserted into dissolution jar containing $900 \mathrm{~mL}$ of $0.01 \mathrm{~N} \mathrm{HCl}$. Dissolution was performed using the Hanson SR8Plus dissolution tool (Hanson Research, CA, USA) apparatus type II (paddle), $50 \mathrm{rpm}$ mixing speed at $37^{\circ} \mathrm{C}$. Ten $\mathrm{mL}$ of sample was taken at an interval of 5, 10, 15, 20, 30, 45 and 60 minutes and was substituted by $10 \mathrm{~mL}$ of new dissolution medium. The sample solution was filtered using filter paper (steriLUX $0.45 \mu \mathrm{m}$ ). The filtrate was analyzed using UV spectrophotometer $\lambda 276 \mathrm{~nm}^{4,18}$

\section{Effect of Thermal Energy}

\section{RESULTS AND DISCUSSION}

Figure-2 showed that both ingredients, ciprofloxacin $\mathrm{HCl}$ monohydrates, showed similar diffractograms. According to Bragg law, when an X-ray is fired on crystalline material of ciprofloxacin $\mathrm{HCl}$, then it will produce a unique diffraction pattern. This pattern is resulted according to the atomic structure of the said crystal. The crystallinity of ingredient A was $82.8 \%$ and B $82.2 \%$. Both ingredients showed no difference before treatment. Heating treatment at $40^{\circ} \mathrm{C}$ did not show any changes in both samples while starting from 
RASĀYAN J. Chem.

Vol. 12 | No. 4 |1973 - 1984| October - December | 2019

110 and $180^{\circ} \mathrm{C}$, both samples showed changes in diffraction peak pattern. This was due to heat energy produced at $40^{\circ} \mathrm{C}$ is not enough to induce transformation in the manufacturing process of ciprofloxacin $\mathrm{HCl}$ monohydrate. Meanwhile, 110 and $180^{\circ} \mathrm{C}$ temperature caused ciprofloxacin $\mathrm{HCl}$ monohydrate to change into anhydrate form, which was shown by a new peak at $2 \theta \pm 12$ and $16^{\circ}$ and the loss of peak at $2 \theta$ in $21^{\circ} .{ }^{19}$

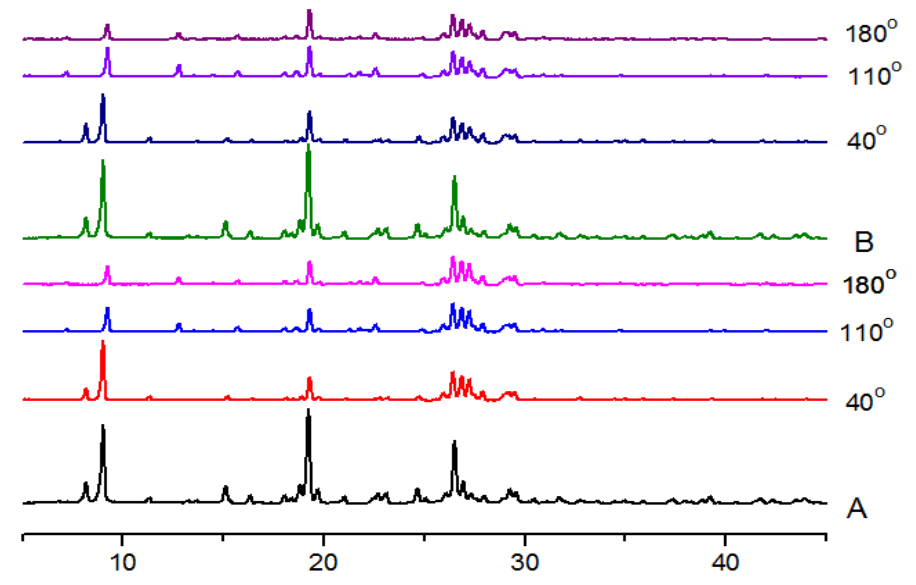

$2 \theta$

Fig.-2: X-ray Diffraction Pattern of Ciprofloxacin $\mathrm{HCl}$ Monohydrate After Thermal Energy

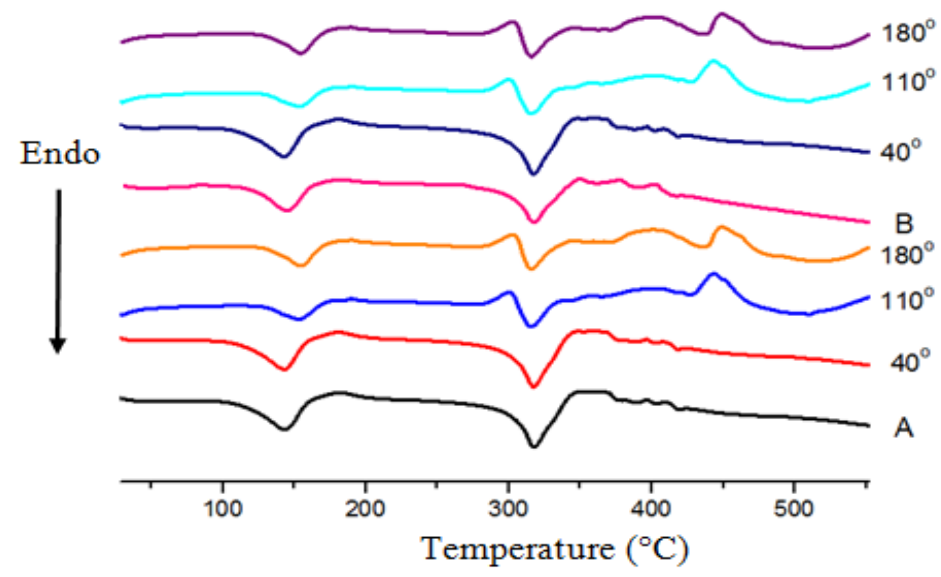

Fig.-3: DSC of Ciprofloxacin $\mathrm{HCl}$ Monohydrate After Thermal Energy

Figure-3 showed the DSC thermogram curve from ciprofloxacin $\mathrm{HCl}$ monohydrate. DSC is thermal analysis methods are a well-established technique in research. The result of calorimetric measurements is a DSC curve shown as the temperature/time dependence on the heat flux (per time unit). ${ }^{20}$ Ingredient A showed the first endothermic curve at $143.41^{\circ} \mathrm{C}(\Delta \mathrm{H}=-1.21 \mathrm{~J} / \mathrm{g})$ which was suspected to be caused by dehydration. The exothermic curve followed at $180^{\circ} \mathrm{C}(\Delta \mathrm{H}=+9.88 \mathrm{~J} / \mathrm{g})$ which showed crystallization. The second endothermic curve at $318.82^{\circ} \mathrm{C}(\Delta \mathrm{H}=-1.70 \mathrm{~J} / \mathrm{g})$ showed the melting temperature of the crystal formed accompanied by decomposition. Dehydration occurred at $\pm 142-144^{\circ} \mathrm{C}$ as shown on DSC thermogram. The thermogram curve of samples $\mathrm{A}$ and $\mathrm{B}$ at $40^{\circ} \mathrm{C}$ showed no changes. Meanwhile, endothermic curve shift to the right occurred at 110 and $180^{\circ} \mathrm{C}$. Without exothermic curve at $180^{\circ} \mathrm{C}$, shifting occurred at $300^{\circ} \mathrm{C}$ with lower endothermic curve. At $180^{\circ} \mathrm{C}$ heating, thermogram of sample showed exothermic curve, which showed the formation of new crystal structure without water or anhydrates. At $180^{\circ} \mathrm{C}$, ciprofloxacin $\mathrm{HCl}$ monohydrate can release its hydrate water to create ciprofloxacin $\mathrm{HCl}$ anhydrate. According to Kakkar et al. ${ }^{21}$, ciprofloxacin $\mathrm{HCl}$ monohydrate is categorized as channel hydrates. Therefore, water molecules can easily bond and detached from ciprofloxacin $\mathrm{HCl}$ monohydrate without damaging its crystal structure. 
RASĀYAN J. Chem.

Vol. 12 | No. 4 |1973 - 1984| October - December | 2019

\section{Effect of Mechanical Energy Effect of Grinding}

Based on the crystal habit of ciprofloxacin $\mathrm{HCl}$ monohydrate observed using SEM as depicted on Fig.-4, both ingredients had both acicular (needle) shape, formed from prismatic crystal which grew lengthways, thus looking like a needle. Crystal habit A was sharper and narrower compared to crystal habit B. Fig.-4 showed grinding result for 180 minutes which caused decrease particle size, accompanied by damage to crystal structure and decrease crystallinity. Fig. $-4 \mathrm{~A}_{1}$ and $\mathrm{B}_{1}$ depicted crystal habit after 60 minutes of grinding which showed no changes in habit shape, which means that only the sharp ends became flat. Fig.- $-4 A_{2}$ and $B_{2}$, the result of grinding for 120 minutes, showed changes in agglomeration shape of long rod shape. Meanwhile, grinding for 180 minutes showed a flatter and wider A and B was dominated by needle shape and were more stable during grinding.
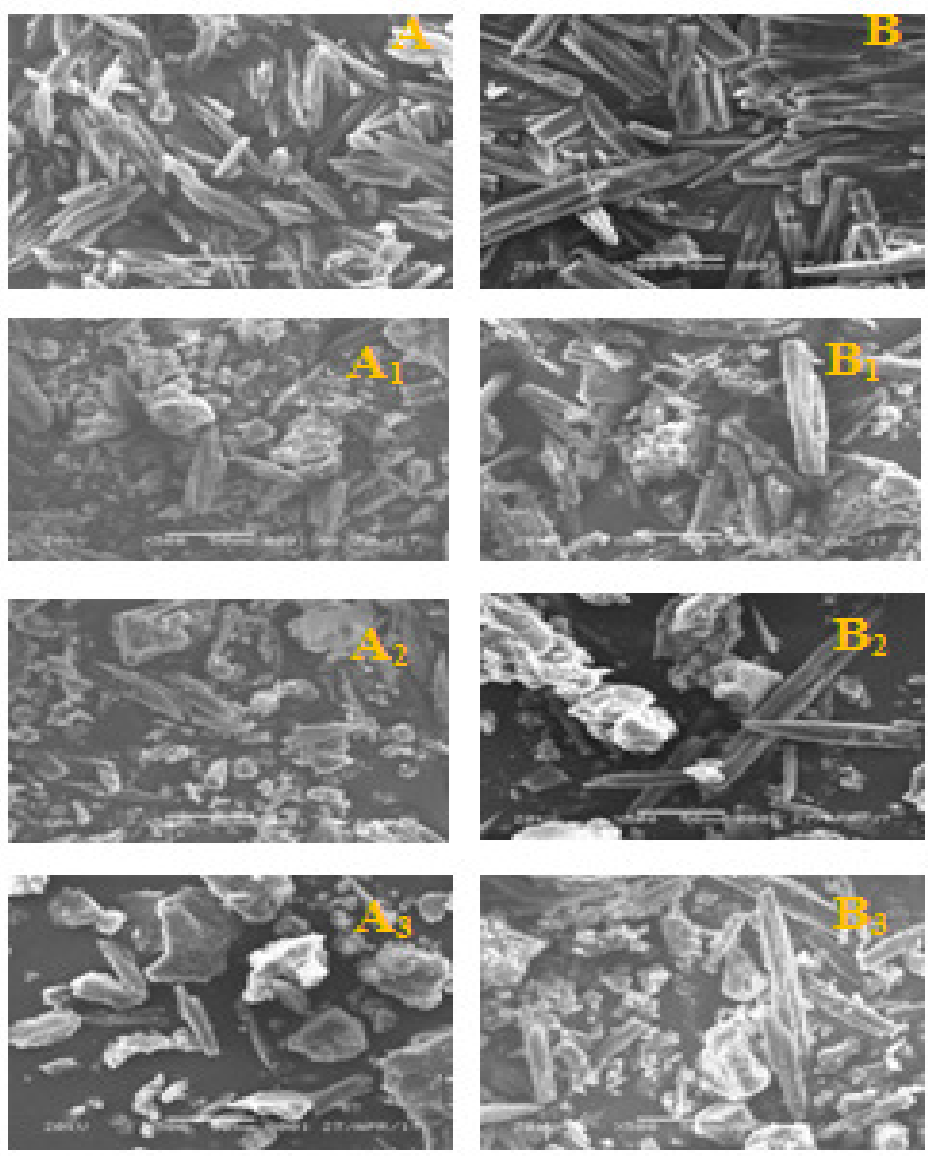

Fig.-4: Photomicrograph of SEM for Ciprofloxacin $\mathrm{HCl}$ Monohydrate Before Grinding (A And B) And After Grinding $\left(A_{1}\right.$ And $\left.B_{1}\right)$ For 60 Minutes, $\left(A_{2}\right.$ And $\left.B_{2}\right)$ For 120 Minutes, And $\left(A_{3}\right.$ And $\left.B_{3}\right)$ For 180 Minutes

According to Fig.-5, the longer the grinding process, the wider the intensity of ciprofloxacin $\mathrm{HCl}$ monohydrate peaks, which indicated a decrease in crystallinity. Decrease crystallinity with the addition of grinding period can be seen in Table-1. This was caused by the looseness of the lattice plane of ciprofloxacin $\mathrm{HCl}$ monohydrate. In this case, higher mechanical energy was needed to damage crystal structure above its critical limit, thus creating amorphous shape. ${ }^{22}$

Table-1: Crystallinity Percentage of Ciprofloxacin HCl Monohydrate After Grinding

\begin{tabular}{cccccccc}
\hline Sample & \multicolumn{7}{c}{ Crystallinity (\%) } \\
\cline { 2 - 8 } & $00^{\prime}$ & $30^{\prime}$ & $60^{\prime}$ & $90^{\prime}$ & $120^{\prime}$ & $150{ }^{\prime}$ & $180^{\prime}$ \\
\hline A & 82.8 & 81.8 & 81.2 & 80.4 & 79.0 & 77.6 & 76.8 \\
\hline B & 82.2 & 81.2 & 80.8 & 80.5 & 79.2 & 78.4 & 75.7 \\
\hline
\end{tabular}




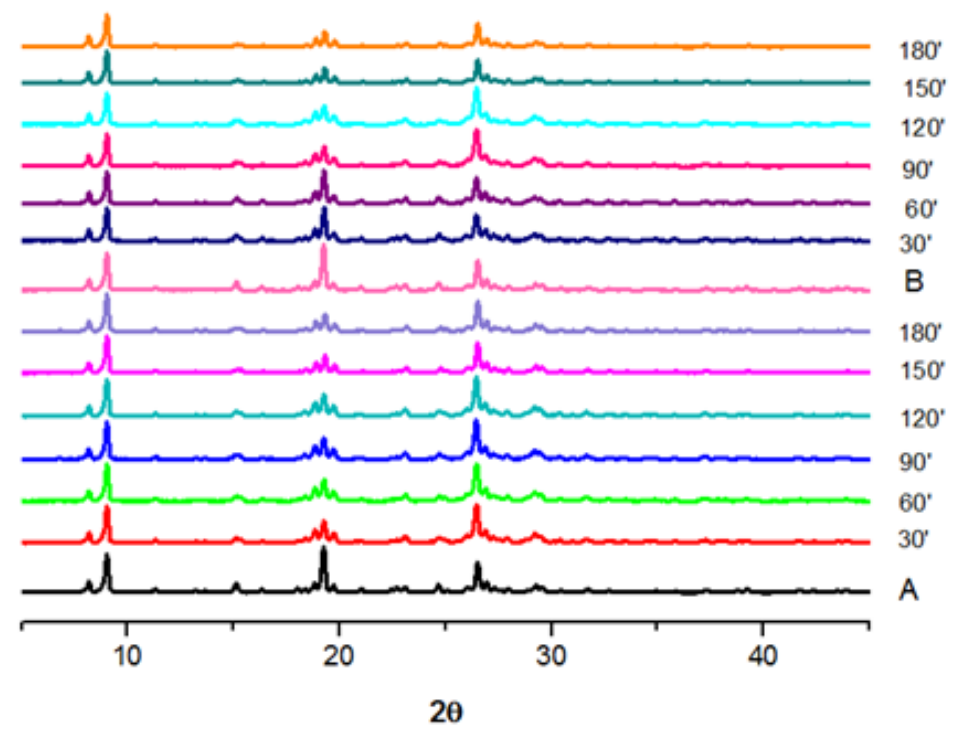

Fig.-5: X-ray Diffraction Pattern of Ciprofloxacin $\mathrm{HCl}$ Monohydrate After Grinding

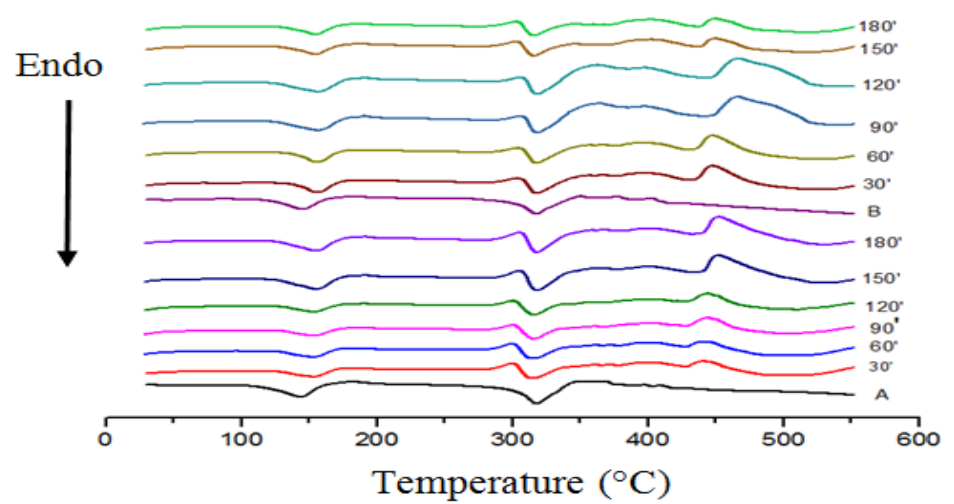

Fig.-6: DSC of Ciprofloxacin $\mathrm{HCl}$ Monohydrate After Grinding

Figure-6 showed a thermogram identical to heating results at 110 and $180^{\circ} \mathrm{C}$, which showed an endothermic curve which was an indicator of shifting crystallization to $300^{\circ} \mathrm{C}$. In the first endothermic curve, shifting occurred to $162^{\circ} \mathrm{C}$. Longer duration of grinding can decrease crystallinity, which can also be seen from the endothermic curve that shifted to the left, in line with increasing grinding duration.

Dissolution result, according to Noyes-Whitney equation, showed that the lower the particle size, the higher the surface area, thus the higher the dissolution rate. Decrease crystallinity by grinding can also increase the dissolution rate and higher free energy. Therefore, it is unstable thermodynamically. ${ }^{23}$ This was following the dissolution result in Fig.-7. There was a difference in dissolution rate between baseline ciprofloxacin $\mathrm{HCl}$ powder and the result of 180 minutes grinding to ingredient $\mathrm{A}$ and $\mathrm{B}$. This was caused by smaller particle size and decrease crystallinity.

\section{Effect of Compression Force}

The relatively high interparticle force caused ciprofloxacin $\mathrm{HCl}$ monohydrate to have poor flow property. On the other hand, ciprofloxacin $\mathrm{HCl}$ monohydrate is relatively easy to compress. Both ingredients showed similar modulus of elasticity curve (Fig.-8). Modulus of elasticity measurement was performed, as an extrapolation from compactness measurement of ingredients when compressed. Ciprofloxacin $\mathrm{HCl}$ monohydrate can be compressed using $4.9 \mathrm{kN}$ pressure and reached maximum tensile strength at $19.6 \mathrm{kN}$ pressure. Pressure administration from 4.9 to $19.6 \mathrm{kN}$ showed that ciprofloxacin $\mathrm{HCl}$ monohydrate was in 
RASĀYAN J. Chem.

Vol. 12 | No. 4 |1973 - 1984| October - December | 2019

the plastic and flowing phase. When given higher force, ciprofloxacin $\mathrm{HCl}$ monohydrate underwent fatigue and fracture phase.

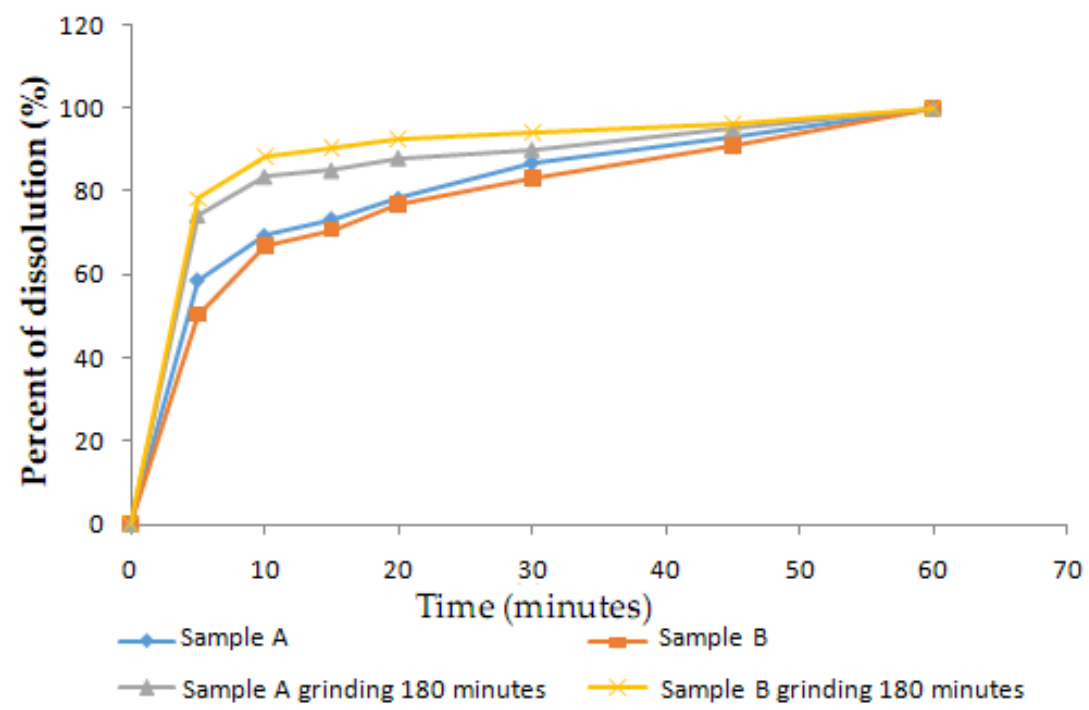

Fig.-7: Dissolution Profile of Ciprofloxacin $\mathrm{HCl}$ Monohydrate After Grinding

Ciprofloxacin $\mathrm{HCl}$ monohydrate powder was pressed using several compression forces, then its physicochemical properties were observed. The pressure was chosen according to the elasticity curve, i.e. 4.9; 19.6; and $24.5 \mathrm{kN}$. These three numbers were chosen because they represented critical pressure in elastic modulus curve changes of ciprofloxacin $\mathrm{HCl}$ monohydrate.

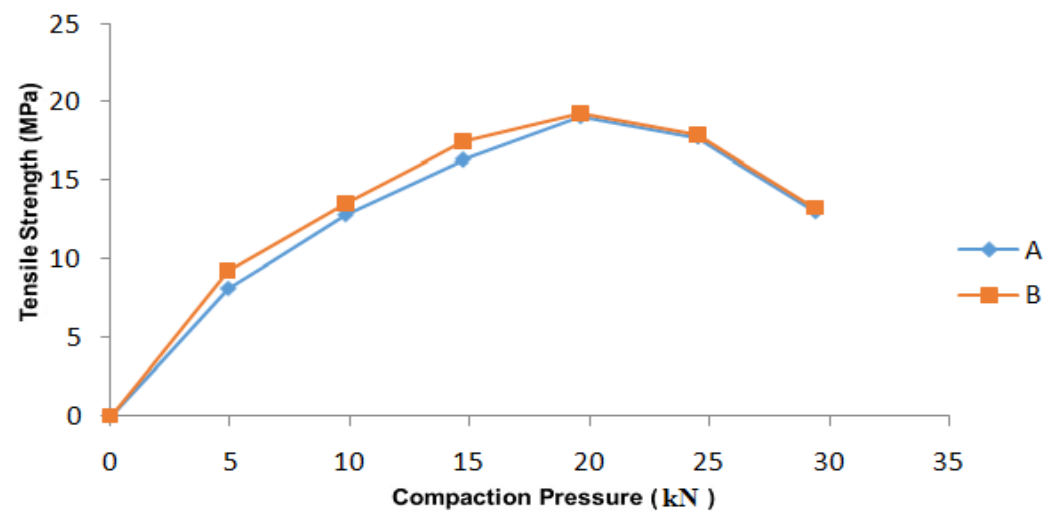

Fig.-8: Elastic Modulus Curve of Ciprofloxacin HydrochlorideHCl Monohydrate

Table-2: Crystallinity Percentage of Ciprofloxacin $\mathrm{HCl}$ Monohydrate After Compression

\begin{tabular}{c|c|c|c|c}
\hline \multirow{2}{*}{ Sample } & \multicolumn{4}{|c}{ Crystallinity (\%) } \\
\cline { 2 - 5 } & $0 \mathrm{kN}$ & $4.9 \mathrm{kN}$ & $19.6 \mathrm{kN}$ & $24.5 \mathrm{kN}$ \\
\hline $\mathrm{A}$ & 82.8 & 78.4 & 74.2 & 73.9 \\
\hline $\mathrm{B}$ & 82.6 & 78.1 & 74.3 & 73.8 \\
\hline
\end{tabular}

XRD diffraction pattern in Fig.-9 and Table-2 showed that ciprofloxacin $\mathrm{HCl}$ monohydrate powder after the compression process led to decreased crystallinity in certain peaks of ciprofloxacin $\mathrm{HCl}$ monohydrate at $2 \theta 15,17$, and $18.5^{\circ}$. This decrease of crystallinity during the compression process was caused by a weakened crystallinity degree.

DSC thermogram in Fig.-10 depicted $\mathrm{A}$ and $\mathrm{B}$ after the compression process in three different compression force variations. In line with the thermogram after grinding and heating at 110 and $180^{\circ} \mathrm{C}$, compression results also cause endothermic change to $160^{\circ} \mathrm{C}$ and exothermic to $300^{\circ} \mathrm{C}$. The exothermic 
peak at $450^{\circ} \mathrm{C}$ cannot confirm the occurring physics event. Decrease crystallinity can also be seen by decrease endothermic peak at around $300^{\circ} \mathrm{C}$, as decrease melting temperature in line with decrease crystallinity. When the crystallinity of a substance increases, then it's melting point will also increase because its crystal lattices are more organized, thus harder to melt.

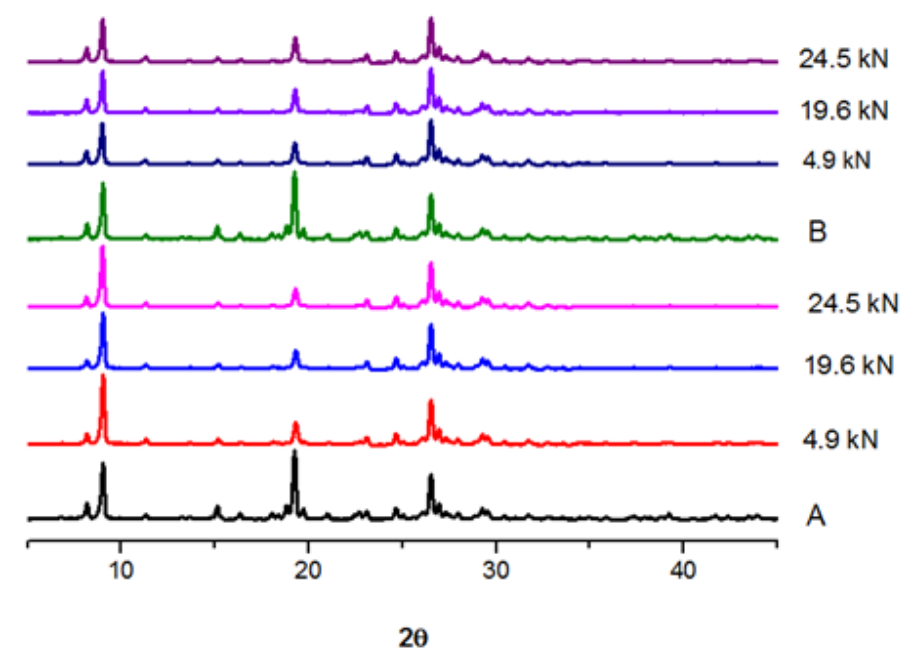

Fig.-9: X-Ray Diffraction Patterns of Ciprofloxacin HCl Monohydrate after Compression Force

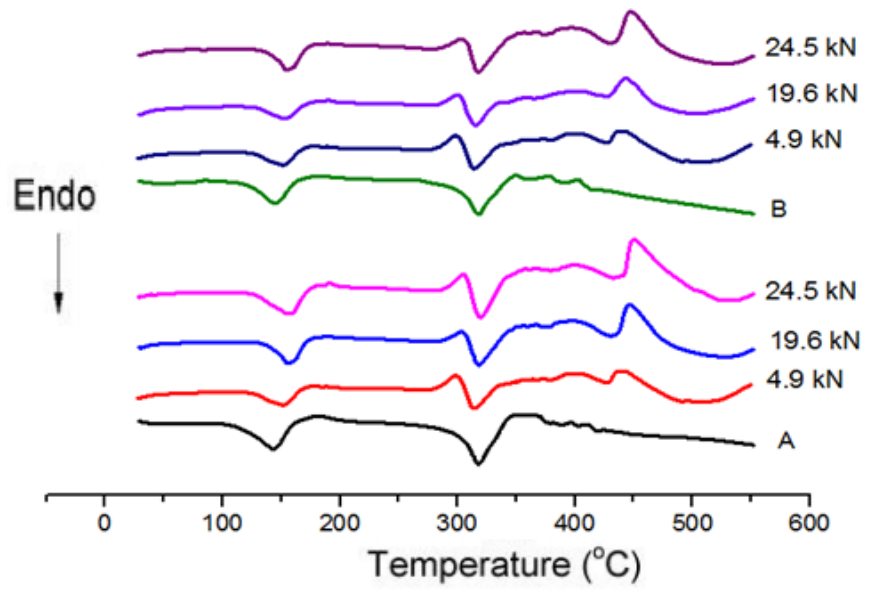

Fig.-10: Thermogram of Ciprofloxacin $\mathrm{HCl}$ Monohydrate Before and After Compression

SEM results analysis depicted in Fig.-11 and Fig.-12 showed that compression caused sintering to ciprofloxacin $\mathrm{HCl}$ monohydrate tablets. This was due to the fusion process, where two or more ciprofloxacin $\mathrm{HCl}$ monohydrate particles fused into one. Smaller particles joining to become bigger caused decreased surface area of ciprofloxacin $\mathrm{HCl}$ monohydrate particles. ${ }^{24}$

The dissolution result in Fig.-13 showed a decrease in the dissolution rate of the compressed powder. This was because the compression force of 4.9-9.8 kN showed elastic-plastic condition, and 14.7-19.6 kN showed plastic condition where particles are bigger in size. Meanwhile, forces at 24.5-29.4 kN resulted in fracture conditions, decrease particle size, decrease interparticle bond and increase dissolution rate.

\section{Effect of Solvent}

There were two types of solvent, i.e. water and ethanol as representatives that can dissolve ciprofloxacin. XRD results can be seen in Fig.-14a which showed that recrystallization results in water solvent produced no changes in diffractogram. Meanwhile, the recrystallization result using ethanol showed new peaks from ciprofloxacin $\mathrm{HCl}$ monohydrate at $2 \theta 8.3,12.1,14.8$, and $16.4^{\circ}$. The formation of this new diffraction pattern indicated changes of ciprofloxacin $\mathrm{HCl}$ from hydrate to anhydrate. Meanwhile, a thermogram from the solvent can be seen in Fig.-14b, which was similar to the result of thermal treatment 


\section{RASĀYAN J. Chem.}

Vol. 12 | No. 4 |1973 - 1984| October - December | 2019

at 110 and $180^{\circ} \mathrm{C}$. Recrystallization result using water also showed endothermic shifting to the right. Sample A showed endothermic shifting to $154.20^{\circ} \mathrm{C}$ and sample B to $155.02^{\circ} \mathrm{C}$. Meanwhile, the result of the thermogram using ethanol also showed endothermic shifting to the right, with sample $\mathrm{A}$ to $155^{\circ} \mathrm{C}$ and sample B to $155.86^{\circ} \mathrm{C}$.
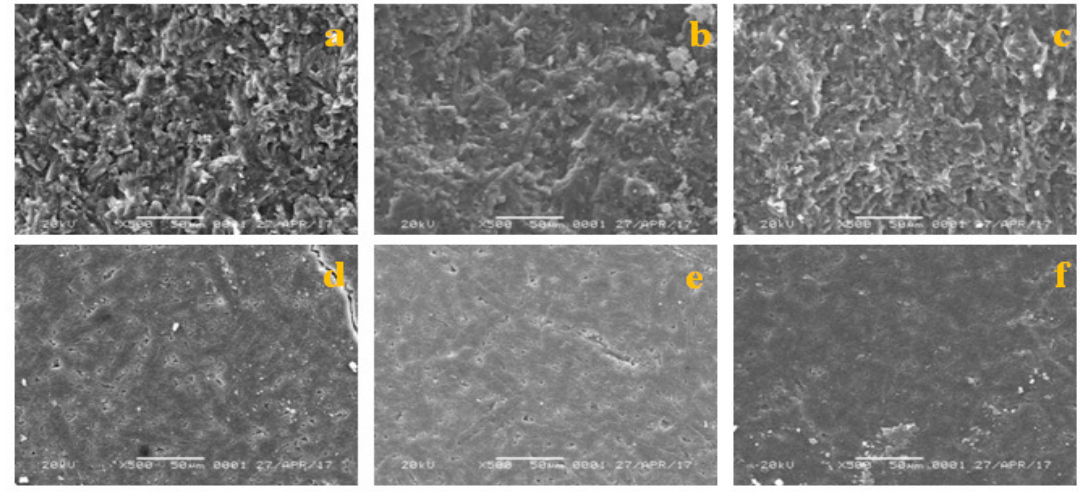

Fig.-11: SEM Photomicrograph Of Ciprofloxacin HCl Monohydrate A. (a), (b), and (c) for Fragment of Tablet, (d), (e), and (f) for Surface of Tablet
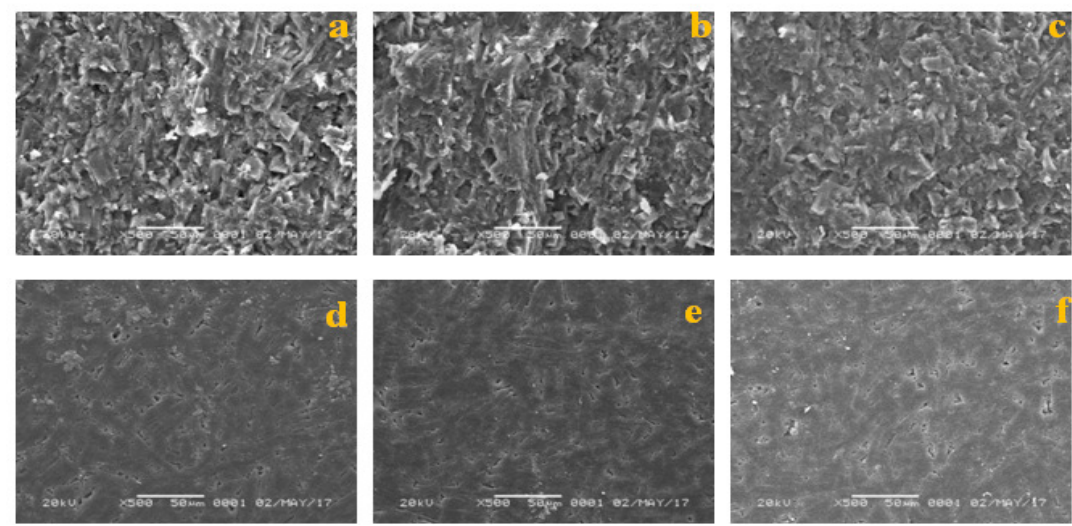

Fig.-12: SEM Photomicrograph Of Ciprofloxacin HCl Monohydrate B. (a), (b), And (c) For Fragment of Tablet, (d), (e), And (f) For Surface of Tablet
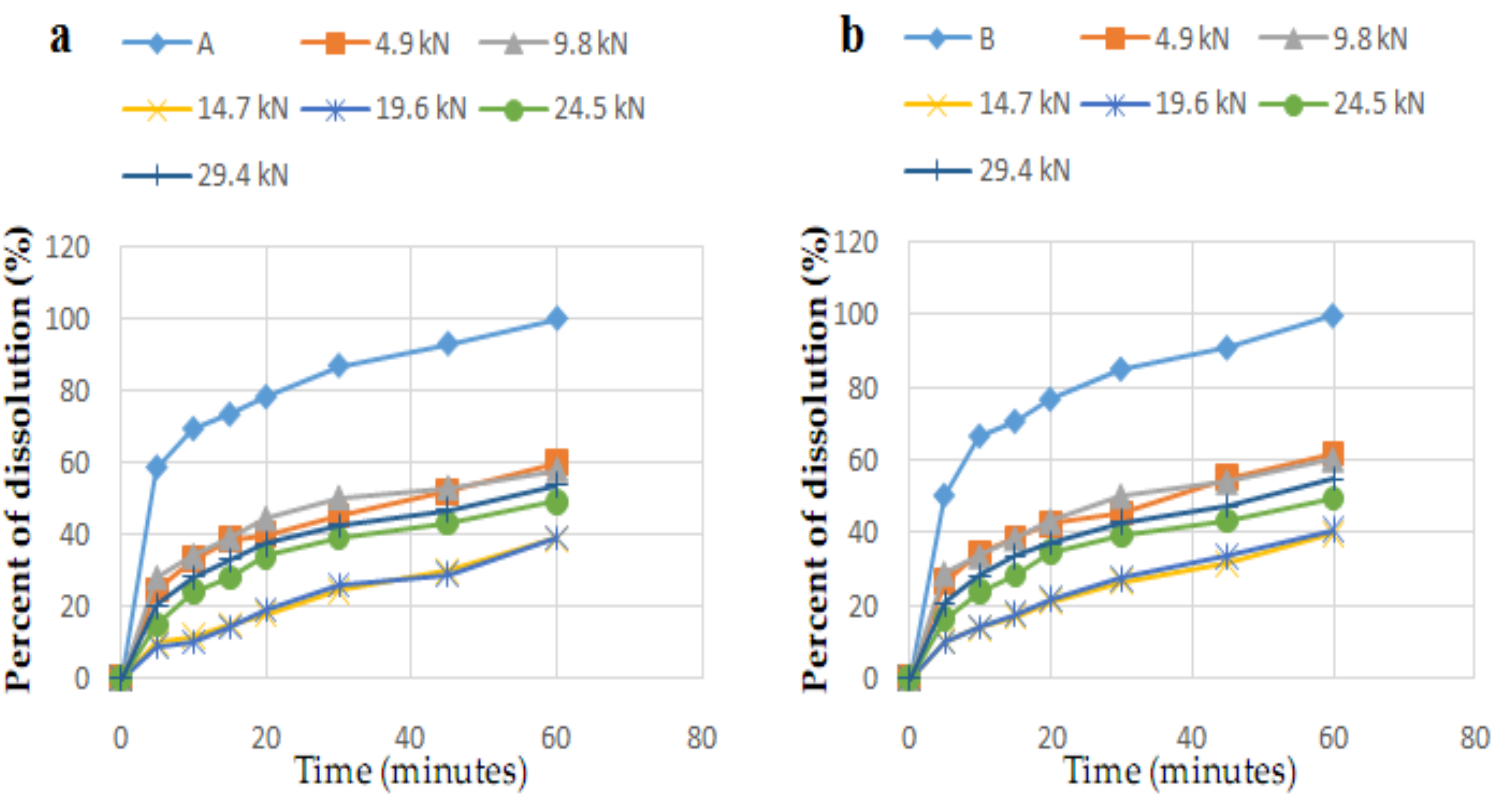

Fig.-13: Dissolution Rate of Ciprofloxacin HCl Monohydrate A And B After Compression 
(a)

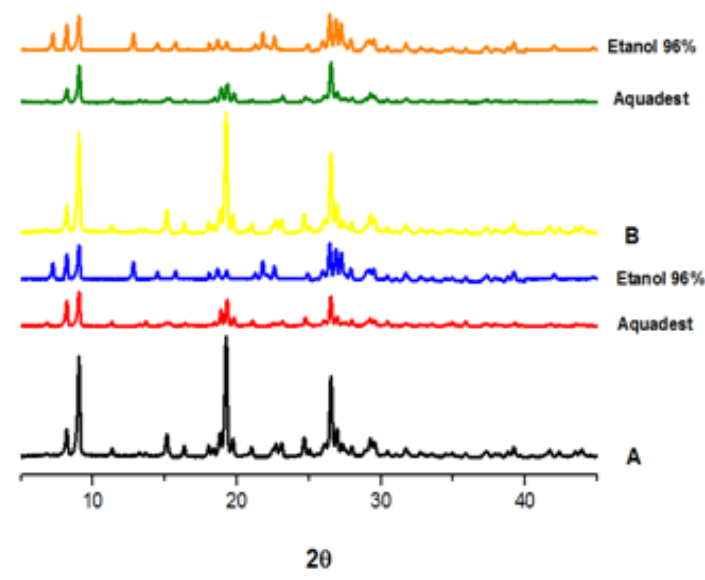

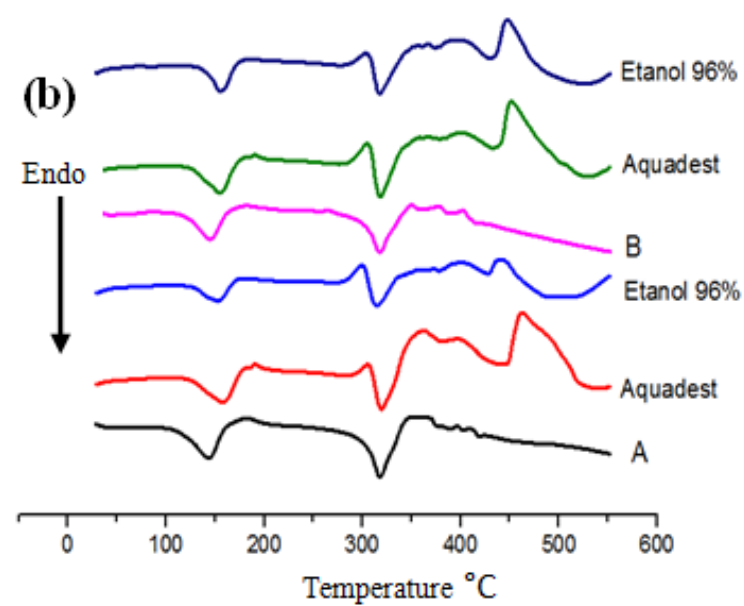

Fig.-14: (a) X-ray Diffraction Patterns and, (b) DSC Thermogram of Ciprofloxacin HCl Monohydrate After Recrystallization

Fig.-15 and 16 showed crystal habits of recrystallization result using water in ingredients A and B which was analyzed using polarization microscope, some of them were shaped like squares and needles. Meanwhile, using $96 \%$ ethanol, the crystal was still in the form of disorganized needles. This was due to differences in solvent polarity during recrystallization, thus produce changes in polar crystal planes and causing different crystal habits. Water solvent was also polar, where crystal polar planes grew larger compared to non-polar planes. Therefore, in acid and polar media, recrystallization results from water solvent showed higher dissolution.
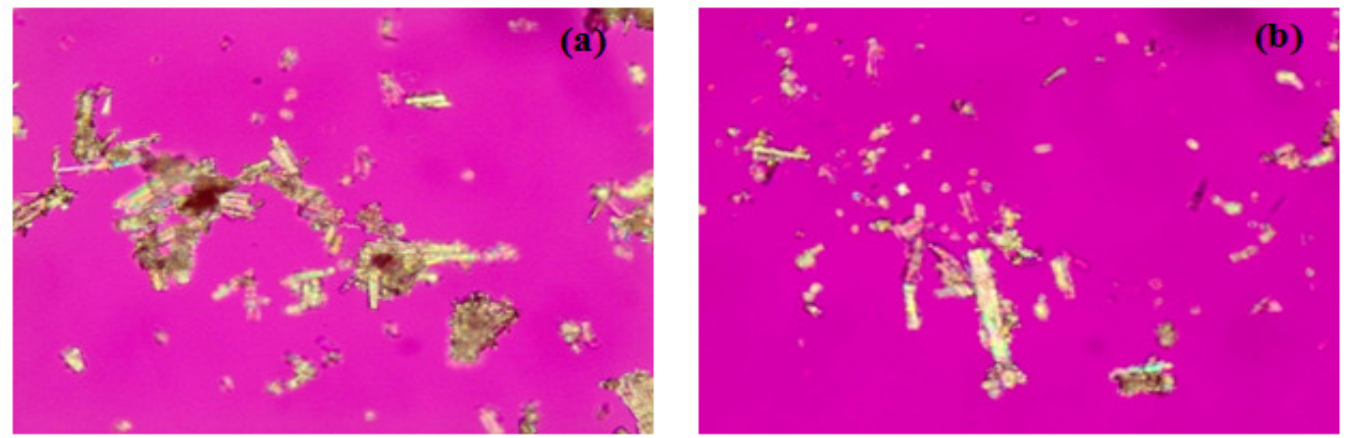

Fig.-15: Crystal Habit of Ciprofloxacin HCl Monohydrate A Using (a) Distilled Water and (b) $96 \%$ Ethanol As Solvent
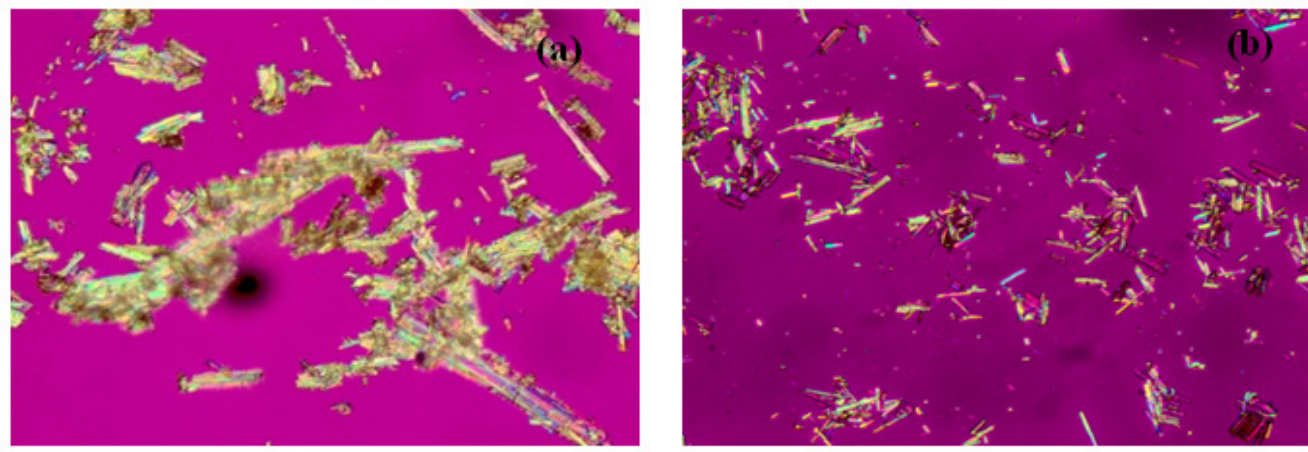

Fig.-16: Crystal Habit of Ciprofloxacin HCl Monohydrate B Using (a) Distilled Water And (b) 96\% Ethanol as Solvent.

The dissolution result also showed that a higher dissolution of water recrystallization was caused by hydrate form of ciprofloxacin, while recrystallization using ethanol decreased dissolution because of the resulted ciprofloxacin was anhydrate, which can be seen in Fig.-17. 
RASĀYAN J. Chem.

Vol. 12 | No. 4 |1973 - 1984| October - December | 2019
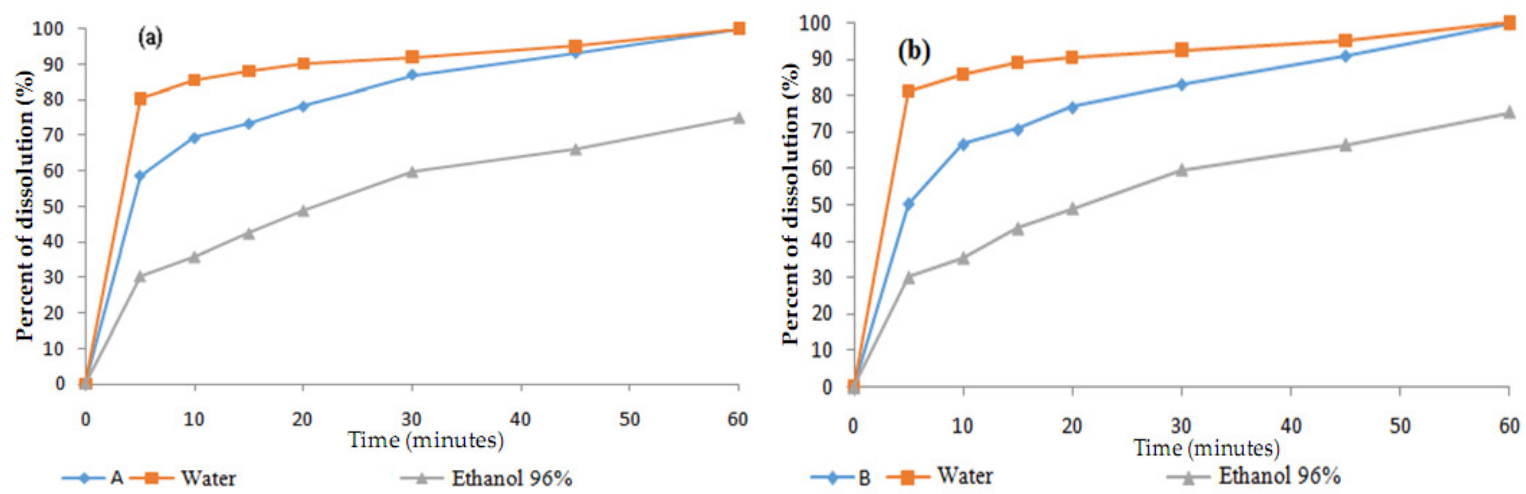

Fig.-17: (a) Dissolution Profile of Ciprofloxacin $\mathrm{HCl}$ Monohydrate A, (b) Dissolution Profile of Ciprofloxacin $\mathrm{HCl}$ Monohydrate B, Both Before And After Recrystallization

\section{CONCLUSION}

Ciprofloxacin $\mathrm{HCl}$ monohydrate ingredient form two different producers showed similarity in physicochemical properties. Manufacturing treatment, which consists of thermal energy, mechanical energy, and solvent affected physicochemical characteristics of ciprofloxacin $\mathrm{HCl}$ monohydrate API. Thermal energy and solvent can change ciprofloxacin from hydrate to anhydrate, thus changing its dissolution rate. Meanwhile, mechanical effect by grinding and compressing can decrease crystallinity and change the particle size of ciprofloxacin $\mathrm{HCl}$ monohydrate, thus changing its dissolution rate. These results showed that the manufacturing process can change the physicochemical characteristics of ciprofloxacin $\mathrm{HCl}$ monohydrate.

\section{REFERENCES}

1. S. Datta and D. J. W. Grant, Nature Reviews Drug Discovery, 3(1), 42(2004), DOI: $10.1038 / \mathrm{nrd} 1280$.

2. L. Fitriani, E. Rismawati, S. Umar and E. Zaini, Rasayan Journal of Chemistry, 11(4), 1643(2018), DOI:10.31788/RJC.2018.1144076.

3. S. R. Vippagunta, H. G. Brittain and D. J. W. Grant, Advanced Drug Delivery Reviews, 48(1), 3(2001), DOI:10.1016/S0169-409X(01)00097-7.

4. M. C. Coelho and N. Harnby, Powder Technology, 20(2), 197(1978), DOI:10.1016/00325910(78)80048-5.

5. United States Pharmacopeial Convention. The United States pharmacopeia; The national formulary. Maryland,1603-1604 (2016)

6. G. G. Z. Zhang, D. Law, E. A. Schmitt and Y. Qiu, Advanced Drug Delivery Reviews, 56(3), 371(2004), DOI:10.1016/j.addr.2003.10.009.

7. P. Di Martino, P. Conflant, M. Drache, J.-P. Huvenne and A.-M. Guyot-Hermann, Journal of Thermal Analysis, 48(3), 447(1997), DOI:10.1007/BF01979491.

8. H. G. Brittain, Journal of Pharmaceutical Sciences, 91(7), 1573(2002), DOI:10.1002/jps.10115.

9. A. Ainurofiq, R. Mauludin, D. Mudhakir and S. N. Soewandhi, Marmara Pharmaceutical Journal, 22(4), 570(2018), DOI:10.12991/jrp.2018.99.

10. G. G. Z. Zhang and D. Zhou, in Developing Solid Oral Dosage Forms (Second Edition), eds. Y. Qiu, Y. Chen, G. G. Z. Zhang, L. Yu and R. V. Mantri, Academic Press, Boston, pp. 23-57 (2017), DOI:10.1016/B978-0-12-802447-8.00002-9.

11. M. Pudipeddi and A. T. M. Serajuddin, Journal of Pharmaceutical Sciences, 94(5), 929(2005), DOI: $10.1002 /$ jps.20302.

12. F. Rahman, A. N. Winantari, D. Setyawan and Siswandono, Asian Journal of Pharmaceutical and Clinical Research, 153(2017), DOI:10.22159/ajpcr.2017.v10i3.15925.

13. I. Sopyan, A. Fudholi, Muchtaridi, I. P. Sari, Journal of Young Pharmacist, 9, 183(2017), DOI:10.5530/jyp.2017.9.36

14. A. Ainurofiq, R. Mauludin, D. Mudhakir and S. N. Soewandhi, Pharmaceutics, 10(3), 85 (2018), DOI:10.3390/pharmaceutics10030085. 


\section{RASĀYAN J. Chem.}

Vol. 12 | No. 4 |1973 - 1984| October - December | 2019

15. R. Censi and P. Di Martino, Molecules, 20(10), 18759(2015), DOI:10.3390/molecules201018759.

16. A. Ainurofiq, R. Mauludin, D. Mudhakir, A. B. Setianto and S. N. Soewandhi, Key Engineering Materials, 787, 43(2018), DOI:10.4028/www.scientific.net/KEM.787.43

17. M. E. Aucamp, W. Liebenberg and N. Stieger, 2015, Solvent-Interactive Transformations of Pharmaceutical Compounds. in Advanced Topics in Crystallization, ed. Y. Mastai, In Tech, pp. 1-24. DOI:10.5772/59586.

18. M. V. B. Rao, B. C. K. Reddy, T. Srinivasarao and V. Prasanthi, Rasayan Journal of Chemistry, 2(2), 276(2009)

19. F. E. S. Souza, J. Oudenes, \& B. I. Gorin, US Patent 20080300258A1, (2008).

20. P.R. Rajakumar and R. Nanthini, Rasayan Journal of Chemistry, 4(3), 567(2011)

21. A. P. Kakkar, M. Singh and A. Mendiratta, Drug Development and Industrial Pharmacy, 23(11), 1063(1997), DOI:10.3109/03639049709150494

22. I. Colombo, G. Grassi and M. Grassi, Journal of Pharmaceutical Sciences, 98(11), 3961(2009), DOI: $10.1002 / j p s .21733$

23. B. C. Hancock and M. Parks, Pharmaceutical Research, 17(4), 397(2000), DOI: 10.1023/A:1007516718048

24. A. N. Martin, P. J. Sinko and Y. Singh, 2011, Martin's physical pharmacy and pharmaceutical sciences: physical chemical and biopharmaceutical principles in the pharmaceutical sciences., Lippincott Williams \& Wilkins, Baltimore, MD, pp. 442-468.

[RJC-5426/2019] 